\title{
SCIENTIFIC-PRACTICAL BASIS OF PREPARATION «EKOFILTRUM» IN BROILER PRODUCTION
}

\author{
НАУЧНО-ПРАКТИЧЕСКОЕ ОБОСНОВАНИЕ ИСПОЛЬЗОВАНИЯ ПРЕПАРАТА \\ «ЭКОФИЛЬТРУМ» В БРОЙЛЕРНОМ ПТИЦЕВОДСТВЕ
}

\section{Chervonova, Post-graduate student}

И.В. Червонова, аспирант

\section{Buyarov, Doctor of Agricultural Sciences}

B.С. Буяров, доктор сельскохозяйственных наук

Orel State Agrarian University, Orel City, Russia

Орловский государственный аграрный университет, г. Орёл, Россия

Phone: +7 (920) 081-78-85, E-mail: katya_che@bk.ru, bvc5636@mail.ru

Received April 11, 2012

\section{АННОТАЦИЯ}

В статье рассмотрена эффективность применения препарата «Экофильтрум» при включении его в рациион иуыплят-бройлеров кросса «Росс-308». Авторами изучено влияние добавки на зоотехнические показатели выращчивания птицы, морфологические и биохимические показатели крови, а также на качество мяса изыплят-бройлеров.

\section{ABSTRACT}

The article describes effectiveness of "Ekofiltrum» when included in the diet of broiler cross "Ross-308». The authors studied effect of additives on the zootechnical performance of poultry, morphological and biochemical parameters of blood, as well as meat quality of broiler chickens.

\section{КЛЮЧЕВЫЕ СЛОВА}

Мясо; Животноводство; Качество.

\section{KEY WORDS}

Meat; Livestock; Quality.

В нашей стране уделяется повышенное внимание увеличению производства животноводческой продукции. В первую очередь это относится к бройлерному птицеводству как наиболее скороспелой, наукоемкой и высокотехнологичной отрасли [3]. За короткое время только птицеводство способно обеспечить потребительский рынок недорогим диетическим мясом $[2,5,8]$.

Одной из основных задач птицеводческой отрасли является повышение продуктивности птицы и рентабельности производства. Эта задача может быть решена за счет более высокой эффективности использования питательных веществ корма. Применение биологически активных доба- вок, стимулирующих переваримость и использование питательных веществ из рациона, можно назвать перспективным направлением в бройлерном птицеводстве $[9,10]$.

Включение в рацион птицы биологически активных добавок позволяет не только повысить эффективность производства, но и способствует получению экологически безопасной для человека продукции $[4,7]$. К таким добавкам можно отнести ферментные, про- и пребиотические препараты, сорбенты. У этих препаратов двойное действие. Во-первых, они улучшают качественные показатели роста цыплят-бройлеров. Во-вторых, они создают 
своеобразную лечебно-профилактическую защиту молодого организма от патогенных воздействий внешней среды [6]. Ко всему прочему включение пребиотиков в рацион цыплят-бройлеров способствует активному росту полезной микрофлоры кишечника, в первую очередь, бифидобактерий и лактобактерий [1].

Важную роль в кормлении бройлеров играют и комплексные препараты, состоящие из нескольких компонентов.

Экофильтрум - уникальный комплексный препарат на основе сорбента лигнина и пребиотика лактулозы. Лигнин эффективный и безопасный сорбент, природный полимер растительного происхождения. Он обладает высокой сорбционной емкостью, сорбирует и выводит из организма различные токсины. Лактулоза пребиотик с наивысшим индексом пребиотической активности, синтетический дисахарид, стимулирует рост лакто- и бифидобактерий в толстом кишечнике. Лактулоза способствует восстановлению нормофлоры, угнетению роста условно-патогенной микрофлоры, улучшению усвоения питательных веществ, повышению иммунитета.

Цель проведенных исследований состояла в изыскании и разработке способа увеличения продуктивности, сохранности цыплят-бройлеров, улучшения качества продукции и повышения рентабельности отрасли за счет использования комплексного препарата «Экофильтрум».

Материалы и методы исследований. Экспериментальная часть работы выполнена на птицефабрике СП «Фабрика по производству мяса птицы» ОАО АПК «Орловская Нива» в 2011 г. Был проведен научно-хозяйственный опыт и производственная проверка. Для научнохозяйственного опыта было сформировано 4 группы из суточных цыплят-бройлеров кросса «Росс-308» по 50 голов в каждой группе, аналогичных по живой массе и клинико-физиологическому состоянию. Основные условия содержания цыплят были одинаковы для всех групп и соответствовали «Руководству по выращиванию бройлеров «Росс-308» и рекомендациям ВНИТИП. Схема опыта представлена в таблице 1.
Для производственной проверки было сформировано 2 группы: контрольная и опытная по 3000 голов в каждой. Цыплята опытной группы получали комбикорма с рациональной дозой препарата «Экофильтрум», выявленной в предыдущем опыте: с 1-го дня жизни и до окончания откорма в количестве 0,8 кг препарата на 1 т комбикорма.

Таблица 1 - Схема опыта

\begin{tabular}{|c|c|}
\hline Группы & Особенности кормления \\
\hline $\begin{array}{l}\text { 1-я кон- } \\
\text { трольная }\end{array}$ & $\begin{array}{l}\text { Основной рацион без использования } \\
\text { препаратов }\end{array}$ \\
\hline 2-я опытная & $\begin{array}{l}\text { Основной рацион + } 0,4 \text { кг препарата } \\
\text { «Кофильтрум» на } 1 \text { т комбикорма }\end{array}$ \\
\hline 3-я опытная & $\begin{array}{l}\text { Основной рацион + } 0,8 \text { кг препарата } \\
\text { «кофильтрум» на } 1 \text { т комбикорма }\end{array}$ \\
\hline 4-я опытная & $\begin{array}{l}\text { Основной рацион + 1,6 кг препарата } \\
\text { «Экофильтрум» на } 1 \text { т комбикорма }\end{array}$ \\
\hline
\end{tabular}

Цыплят-бройлеров в обеих сериях опытов выращивали до 38-дневного возраста на подстилке. Препарат вводили в состав комбикорма на предприятии путем ручного смешивания непосредственно перед кормлением птицы. Вся птица подвергалась ветеринарно-профилактическим мероприятиям в соответствии со схемой, принятой на птицефабриках.

Зоотехнические показатели определяли с использованием общепринятых методов исследования. Анатомическую разделку тушек проводили согласно методическим рекомендациям ВНИТИП (Т.А. Столляр и др., 1994; В.С. Лукашенко и др., 2001). Морфо-биохимические показатели крови определяли на базе инновационного научно-исследовательского испытательного центра ФГБОУ ВПО Орел ГАУ с помощью гемоанализатора «Abacus junior vet» и биохимического анализатора «Clima MC $15 »$.

В мясе определяли: содержание влаги, количество сухих веществ высушиванием навески мяса в сушильном шкафу до постоянной массы при температуре 102$105^{\circ} \mathrm{C}$; сырой протеин - по методу Къельдаля; сырой жир - по методу Сокслета; триптофан - по методике, основанной на цветной реакции между продуктами распада триптофана и парадиметиламинобензальдегидом и оксипролин - по методу Стеджемана-Стальдера (А.Т. Мысик и др., 1985). 
Результаты и их обсуждение.

1. Зоотехнические показатели выращивания цыплят-бройлеров.

Основные зоотехнические показатели выращивания цыплят-бройлеров представлены в таблице 2. Установлено, что включение в рацион бройлеров препарата «Экофильтрум» способствовало увеличению их живой массы. Так, во 2-й группе увеличение составило $1,66 \%$, в 3-й $-6,64 \%$ $(\mathrm{P}<0,001)$, а в 4-й $-5,9 \%(\mathrm{P}<0,001)$.
Среднесуточный прирост во всех опытных группах был выше контроля и составил 54,1-56,8 г против 53,2 г в контрольной группе.

В результате применения препарата «Экофильтрум» увеличилась и сохранность цыплят-бройлеров с 94\% (контрольная группа) до 98\% (3-я и 4-я группы). 3атраты корма во всех опытных группах были ниже данного показателя в контрольной группе: во 2-й - на 1,64\%, в 3-й - на 6,01\% и в 4 -й опытной группе - на 5,46\%.

Таблица 2 - Зоотехнические показатели выращивания цыплят-бройлеров за 38 дней $(\mathrm{M} \pm \mathrm{m} ; \mathrm{n}=50)$

\begin{tabular}{|c|c|c|c|c|}
\hline \multirow{2}{*}{ Показатели } & \multicolumn{4}{|c|}{ Группы } \\
\hline & 1-K. & 2-оп. & 3-оп. & 4-оп. \\
\hline $\begin{array}{l}\text { Средняя живая масса суточного цы- } \\
\text { пленка, г }\end{array}$ & $40,0 \pm 0,12$ & $40,1 \pm 0,11$ & $40,3 \pm 0,10$ & $40,2 \pm 0,09$ \\
\hline Средняя живая масса 1 гол., г & $2061,6 \pm 23,4$ & $2095,8 \pm 22,4$ & $2198,4 \pm 20,6^{* * *}$ & $2183,2 \pm 24,5^{* * *}$ \\
\hline Среднесуточный прирост, Г & 53,2 & 54,1 & 56,8 & 56,4 \\
\hline $\begin{array}{l}\text { Затраты корма на } 1 \text { кг прироста жи- } \\
\text { вой массы, кг }\end{array}$ & 1,83 & 1,80 & 1,72 & 1,73 \\
\hline Coxpaнность, \% & 94,0 & 96,0 & 98,0 & 98,0 \\
\hline Индекс продуктивности, ед. & 278,26 & 293,79 & 330,29 & 325,69 \\
\hline
\end{tabular}

Примечание: *** - $\mathrm{P}<0,001$

Эффективность производства мяса бройлеров характеризует индекс продуктивности. В опытных группах он составил 293,79-330,29 ед. Самый высокий показатель индекса продуктивности получен в 3-й опытной группе - 330,29 ед.
2. Морфологические и биохимические показатели крови.

Полученные нами морфологические и биохимические показатели крови цыплятбройлеров находились в пределах физиологической нормы (табл. 3).

Таблица 3 - Морфологические и биохимические показатели крови цыплят-бройлеров (возраст - 38 суток; $\mathrm{M} \pm \mathrm{m} ; \mathrm{n}=10$ )

\begin{tabular}{|c|c|c|c|c|}
\hline \multirow{2}{*}{ Показатели } & \multicolumn{4}{|c|}{ Группы } \\
\hline & $1-\mathrm{K}$. & 2-оп. & 3-оп. & 4-оп. \\
\hline Эритроциты, $10^{12} /$ л & $2,54 \pm 0,11$ & $2,63 \pm 0,10$ & $2,97 \pm 0,09^{* *}$ & $2,95 \pm 0,08^{* *}$ \\
\hline Гемоглобин, г/л & $89,0 \pm 3,10$ & $94,21 \pm 2,97$ & $98,34 \pm 2,63^{*}$ & $98,27 \pm 3,15^{*}$ \\
\hline Тромбоциты, $10 \%$ л & $65,64 \pm 4,15$ & $70,30 \pm 3,69$ & $62,51 \pm 3,81$ & $67,92 \pm 3,56$ \\
\hline Лейкоциты, $10 \%$ /л & $28,16 \pm 0,93$ & $30,25 \pm 1,28$ & $29,04 \pm 1,42$ & $28,39 \pm 1,67$ \\
\hline Общий белок, г/л & $43,38 \pm 1,54$ & $44,50 \pm 1,67$ & $47,87 \pm 1,29^{*}$ & $46,04 \pm 1,38$ \\
\hline Альбумин, Г/л & $14,74 \pm 0,53$ & $15,58 \pm 0,62$ & $16,70 \pm 0,49^{*}$ & $16,14 \pm 0,38^{*}$ \\
\hline Глобулины, Г/л & $28,64 \pm 0,87$ & $28,92 \pm 1,12$ & $31,17 \pm 0,75^{*}$ & $29,90 \pm 1,28$ \\
\hline БАСК, \% & $42,83 \pm 1,02$ & $44,82 \pm 0,87$ & $46,54 \pm 0,69 * *$ & $45,94 \pm 0,70^{*}$ \\
\hline ЛАСК, \% & $29,52 \pm 1,20$ & $32,74 \pm 1,19$ & $35,28 \pm 1,31 * *$ & $36,94 \pm 1,53 * *$ \\
\hline
\end{tabular}

Примечание: * - P $<0,05$; ** - P $<0,01$

Количество эритроцитов было выше в опытных группах на 16,93\% (3-я группа), $16,14 \%$ (4-я опытная) и 2,31\% (2-я группа) по сравнению с контрольной группой. При этом различия в 3-й и 4-й опытных группах были достоверны $(\mathrm{P}<0,01)$. Уровень гемоглобина также был выше во всех опытных группах: во 2-й - на 5,85\%, в 3-й - на $10,49 \%(\mathrm{P}<0,05)$, в 4-й - на $10,42 \%(\mathrm{P}<0,05)$ по сравнению с контролем.

Нами установлено недостоверное повышение числа тромбоцитов во 2-й и 4-й опытных группах в среднем на $5,29 \%$ по сравнению с контролем. Анализ уровня 
лейкоцитов в сыворотке крови показал, что в опытных группах наблюдались незначительные отклонения от контроля, но все значения находились в пределах физиологической нормы.

При исследовании сыворотки крови на содержание общего белка и белковых фракций нами было установлено некоторое повышение показателей белкового обмена в опытных группах. Так, уровень общего белка в опытных группах колебался от 44,50 г/л до 47,87 г/л. Наибольшее его значение отмечено в 3-й опытной группе 47,87 г/л $(\mathrm{P}<0,05)$.

Содержание альбуминов в сыворотке крови было выше во 2-й опытной группе на $5,7 \%$, в 3 -й - на $13,3 \%(\mathrm{P}<0,05)$, в 4-й на $9,5 \%(\mathrm{P}<0,05)$. Количество глобулинов в опытных группах было выше уровня контрольной группы. При этом, в 3-й опытной группе зафиксирована максимальная разница с контролем $-8,83 \%(\mathrm{P}<0,05)$. Повышение уровня общего белка и белковых фракций говорит об улучшении показателей белкового обмена.
Бактерицидная активность сыворотки крови (БАСК) является суммарным показателей неспецифической резистентности организма цыплят-бройлеров, во всех группах она имела показатели выше, чем в контроле. Так, во 2-й группе - на 4,65\%, в 3 -й - на $8,66 \%(\mathrm{P}<0,01)$ и в 4 -й - на $7,26 \%$ $(\mathrm{P}<0,05)$.

Лизоцимная активность сыворотки крови (ЛАСК) в 4-й и 3-й опытных группах была достоверно выше контроля на 19,51 и $25,14 \%(\mathrm{P}<0,01)$ соответственно. Повышение этих показателей в совокупности с другими факторами иммунитета обеспечило более высокую сохранность птицы.

3. Качество мяса иььплят-бройлеров. По окончании научно-хозяйственного опыта был проведен контрольный убой 6 голов цыплят-бройлеров из каждой группы (по 3 головы петушков и курочек, близких к средним показателям живой массы по каждой группе). Полученные результаты анатомической разделки выявили межгрупповые различия по мясным качествам тушек (табл. 4 и 5).

Таблица 4 - Мясные качества тушек петушков

\begin{tabular}{|c|c|c|c|c|}
\hline \multirow{2}{*}{ Показатели } & \multicolumn{4}{|c|}{ Группы } \\
\hline & $1-\mathrm{K}$ & 2-оп. & 3-оп. & 4-оп. \\
\hline Предубойная масса, г & $2177,7 \pm 11,2$ & $2208,7 \pm 13,8$ & $2303,0 \pm 10,2^{* *}$ & $2297,0 \pm 11,6^{* *}$ \\
\hline Масса потрошеной тушки, Г & $1589,7 \pm 10,7$ & $1616,8 \pm 10,7$ & $1697,3 \pm 8,5^{* *}$ & $1686,0 \pm 9,4^{* *}$ \\
\hline Убойный выход, \% & 73,0 & 73,2 & 73,7 & 73,4 \\
\hline Масса съедобных частей, Г & $1270,7 \pm 10$ & $1296,0 \pm 9,0$ & $1377,7 \pm 7,8^{* *}$ & $1364,6 \pm 8,1 * *$ \\
\hline Масса несъедобных частей, Г & $319,0 \pm 2,1$ & $320,8 \pm 2,6$ & $319,6 \pm 2,1$ & $321,4 \pm 1,9$ \\
\hline Отношение съедобных частей к несъедобным & 3,98 & 4,04 & 4,31 & 4,25 \\
\hline Масса мышщ, Г & $978,0 \pm 7,6$ & $1010,3 \pm 6,8^{*}$ & $1081,3 \pm 6,1 * * *$ & $1069,9 \pm 6,5 * * *$ \\
\hline в т.ч. филе & $336,1 \pm 3,3$ & $373,2 \pm 3,1 * *$ & $410,9 \pm 3,5 * * *$ & $400,8 \pm 3,6^{* * *}$ \\
\hline Масса костей, Г & $318,3 \pm 2,08$ & $320,1 \pm 2,45$ & $318,8 \pm 2,17$ & $320,6 \pm 2,62$ \\
\hline Масса внутреннего жира, г & $23,3 \pm 0,43$ & $24,0 \pm 0,41$ & $25,1 \pm 0,48$ & $24,7 \pm 0,42$ \\
\hline \multicolumn{5}{|l|}{ Тушки $(\%)$ : } \\
\hline 1 сорта & 76,6 & 77,0 & 77,8 & 77,5 \\
\hline 2 сорта и промпереработка & 23,4 & 23,0 & 22,2 & 22,5 \\
\hline
\end{tabular}

Примечание: * - P <0,05; ** - P $<0,01$; *** - $\mathrm{P}<0,001$

Как видно из данных таблиц включение препарата «Экофильтрум» в рацион, как петушков, так и курочек, способствовало увеличению предубойной массы цыплятбройлеров. Так, у петушков повышение составило: во 2-й группе - 1,42\%, в 3-й и 4-й группах - 5,75 и $5,48 \%(\mathrm{P}<0,01)$ соответственно; у курочек - $1,76 \%, 7,49$ и $6,31 \%$ $(\mathrm{P}<0,01)$ соответственно во 2-й, 3-й и 4-й опытных группах. Масса потрошеной тушки во всех опытных группах была выше анало- гичного показателя контрольной группы на 1,70 и $2,18 \%, 6,77 \%(\mathrm{P}<0,01)$ и $8,52 \%$ $(\mathrm{P}<0,001), 6,06$ и $6,75 \%(\mathrm{P}<0,01)$ соответственно у петушков и курочек во 2-й, 3-й и 4-й опытных группах. Высокие показатели массы потрошеной тушки и предубойной массы предопределили больший убойный выход в опытных группах - от 73,1 до 73,7\%. При этом самые высокие значения получены в 3-й опытной группе: у петушков $73,7 \%$ и у курочек $-73,5 \%$. 
Таблица 5 - Мясные качества тушек курочек

\begin{tabular}{|c|c|c|c|c|}
\hline \multirow{2}{*}{ Показатели } & \multicolumn{4}{|c|}{ Группы } \\
\hline & 1-К. & 2-оп. & 3-оп. & 4-оп. \\
\hline Предубойная масса, Г & $1950,3 \pm 12,2$ & $1984,7 \pm 13,1$ & $2096,3 \pm 15,2 * *$ & $2073,3 \pm 10,9^{* *}$ \\
\hline Масса потрошеной тушки, Г & $1419,8 \pm 9,5$ & $1450,8 \pm 8,6$ & $1540,8 \pm 9,3 * * *$ & $1515,6 \pm 8,2 * *$ \\
\hline Убойный выход, \% & 72,8 & 73,1 & 73,5 & 73,1 \\
\hline Масса съедобных частей, Г & $1137,8 \pm 7,1$ & $1175,0 \pm 6,5^{*}$ & $1256,5 \pm 8,2 * * *$ & $1229,0 \pm 8,4 * *$ \\
\hline Масса несъедобных частей, Г & $282,0 \pm 2,5$ & $275,8 \pm 2,8$ & $284,3 \pm 2,1$ & $286,6 \pm 2,4$ \\
\hline Отношение съедобных частей к несъедобным & 4,03 & 4,26 & 4,42 & 4,29 \\
\hline Macca мышц, г & $868,8 \pm 6,6$ & $903,1 \pm 7,3^{*}$ & $976,7 \pm 7,7 * * *$ & $955,4 \pm 6,4 * * *$ \\
\hline в т.ч. филе & $302,1 \pm 3,1$ & $336,7 \pm 2,7 * *$ & $377,3 \pm 3,3 * * *$ & $362,5 \pm 3,6^{* * *}$ \\
\hline Масса костей, Г & $281,4 \pm 2,38$ & $275,2 \pm 2,14$ & $283,6 \pm 2,54$ & $286,0 \pm 2,41$ \\
\hline Масса внутреннего жира, Г & $22,8 \pm 0,43$ & $23,4 \pm 0,41$ & $24,3 \pm 0,42$ & $24,0 \pm 0,41$ \\
\hline \multicolumn{5}{|l|}{ Тушки (\%): } \\
\hline 1 сорта & 76,3 & 76,5 & 77,6 & 77,3 \\
\hline 2 сорта и промпереработка & 23,7 & 23,5 & 22,4 & 22,7 \\
\hline
\end{tabular}

Примечание: * - $\mathrm{P}<0,05$; ** - $\mathrm{P}<0,01$; *** - $\mathrm{P}<0,001$

Масса съедобных и несъедобных частей, а также их соотношение являются ценными показателями, дополняющими картину мясных качеств тушек цыплятбройлеров. Наибольшие показатели массы съедобных частей были получены в 3-й и 4-й опытных группах, как у петушков, так и у курочек. Так, у петушков они составили 1377,7 и 1364,6 г, что выше уровня контрольной группы на 107 и 93,9 г $(\mathrm{P}<0,01)$, соответственно в 3-й и 4-й опытных группах. У курочек разница с контрольной группой составила 118,7 г $(\mathrm{P}<0,001)$ в 3-й группе и $91,2 г(\mathrm{P}<0,01)$ в 4-й группе. Масса несъедобных частей в опытных группах находилась в пределах 319,6-321,4 г

у петушков и $275,8-286,6$ г у курочек. Повышение массы съедобных частей в опытных группах в основном обусловлено увеличением массы мышц (в т.ч. и филе), масса несъедобных частей представлена в большей части массой костей. Установлено достоверное увеличение у петушков и курочек в опытных группах массы мышц: на 3,3 и $3,95 \%(\mathrm{P}<0,05)$ во 2-й группе, 10,56 и $12,42 \% \quad(\mathrm{P}<0,001)$ в 3 -й, 9,4 и $9,97 \%$ $(\mathrm{P}<0,001)$ в 4-й опытной группе соответственно. Также наблюдается достоверная разница между 2-й и 3-й, 2-й и 4-й опытными группами. У петушков данная разница соответственно составила 71 и 59,6 г $(\mathrm{P}<0,01)$, а у курочек $-73,6$ и 52,3 г $(\mathrm{P}<0,01)$. По массе филе наблюдалась аналогичная тенденция, самый высокий показатель был получен в 3-й опытной группе и составил у петушков 410,9 г, а у курочек -
377,3 г, что выше контроля на 22,26 и $24,89 \% \quad(\mathrm{P}<0,001)$. Наибольшее значение соотношения массы съедобных и несъедобных частей отмечено также в 3-й опытной группе: 4,31 - у петушков и 4,42 - у курочек.

Достоверных различий по массе внутреннего жира между опытными группами и контролем не было получено. Значения этого показателя колебались у петушков от 23,3 до 25,1 г, а у курочек от 22,8 до 24,3 г.

Тушки цыплят-бройлеров всех групп по показателям упитанности, преимущественно, можно отнести к I сорту (76,3$77,8 \%$ ) и около $23 \%$ - ко II сорту.

Данные по химическому составу мяса бойлеров представлены в табл. 6. Из данной таблицы следует, что наибольшее содержание белка в грудных и ножных мышцах было у петушков и курочек 3-й опытной группы. Так, содержание белка в грудных мышцах у петушков 3-й группы составило $22,87 \%$, что на $1,67 \%$ выше, чем в 1 -й, и на $1,19 \%$, чем во 2-й группе. Уровень белка в грудных мышцах у курочек 3-й группы был равен $23,30 \%$, что на $1,41 \%$ выше, чем в 1-й, и на $1,24 \%$, чем во 2-й группе. Содержание белка в ножных мышцах у петушков находилось на уровне 19,0$20,38 \%$, у курочек - 20,21-21,23\%. При этом курочки превосходили петушков по данному показателю на 0,85-1,21\%.

Самая низкая доля жира - 1,55 и $1,76 \%$, отмечена в грудных мышцах у петушков и курочек 3-й опытной группы. Уровень жира в ножных мышцах у курочек 
изучаемых групп составил $3,35-3,70 \%$, у петушков - 3,17-3,30\%. Следует отметить, что в опытных группах прослеживается тенденция сокращения уровня жира в грудных и ножных мышцах по сравнению с данными, полученными в контроле. Не- высокая жирность мяса при включении препарата «Экофильтрум» в технологию выращивания бройлеров вполне отвечает биологическим требованиям диетического питания.

Таблица 6 - Химический состав и качество мышц цыплят-бройлеров

\begin{tabular}{|c|c|c|c|c|c|c|c|c|}
\hline \multirow{3}{*}{ Показатели } & \multicolumn{8}{|c|}{ Группы } \\
\hline & \multicolumn{2}{|c|}{$1-\mathrm{K}}$. & \multicolumn{2}{|c|}{ 2-oп. } & \multicolumn{2}{|c|}{ 3-оп. } & \multicolumn{2}{|c|}{ 4-оп. } \\
\hline & пет. & кур. & пет. & кур. & пет. & кyp. & пет. & кyp. \\
\hline \multicolumn{9}{|c|}{ Грудные мышцы } \\
\hline Белок & 21,20 & 21,89 & 21,68 & 22,06 & 22,87 & 23,30 & 22,75 & 22,93 \\
\hline Жир & 1,59 & 2,04 & 1,60 & 1,89 & 1,55 & 1,76 & 1,58 & 1,90 \\
\hline \multicolumn{9}{|c|}{ В белке содержится, \% } \\
\hline триптофана & 1,31 & 1,29 & 1,34 & 1,32 & 1,43 & 1,41 & 1,40 & 1,44 \\
\hline оксипролина & 0,22 & 0,21 & 0,22 & 0,20 & 0,21 & 0,21 & 0,21 & 0,21 \\
\hline БКП, ед. & 5,95 & 6,14 & 6,09 & 6,60 & 6,81 & 6,71 & 6,67 & 6,85 \\
\hline \multicolumn{9}{|c|}{ Ножные мышцы } \\
\hline Белок & 19,0 & 20,21 & 19,41 & 20,42 & 20,38 & 21,23 & 20,25 & 20,93 \\
\hline Жир & 3,27 & 3,70 & 3,30 & 3,61 & 3,17 & 3,35 & 3,24 & 3,52 \\
\hline \multicolumn{9}{|c|}{ В белке содержится, \% } \\
\hline триптофана & 1,28 & 1,27 & 1,29 & 1,28 & 1,36 & 1,32 & 1,35 & 1,30 \\
\hline оксипролина & 0,22 & 0,21 & 0,21 & 0,21 & 0,21 & 0,20 & 0,22 & 0,20 \\
\hline БКП, ед. & 5,82 & 6,05 & 6,14 & 6,10 & 6,48 & 6,60 & 6,14 & 6,50 \\
\hline
\end{tabular}

Чем больше в мясе полноценных белков, т.е. незаменимых аминокислот, тем выше его биологическая ценность. Одной из главных характеристик оценки качества мяса является белково-качественный показатель (БКП). Его находят как соотношение аминокислот триптофана и оксипролина. Анализируя полученные результаты, можно отметить, что включение в рацион препарата «Экофильтрум» позволило получить тушки цыплят-бройлеров с большей биологической ценностью мяса. Благодаря данному препарату произошло увеличение триптофана в грудных мышцах (на $0,03-0,12 \%$ у петушков и на $0,03-0,15 \%$ у курочек), вследствие чего повысился и БКП на $0,14-0,86$ и $0,46-0,71$ ед. соответственно у петушков и курочек. Это подтверждает диетические свойства белого мяса птицы.

Также нами были определены показатели сочности и нежности мяса. В результате установлено, что сочность мяса бройлеров опытных групп была несколько выше аналогичного показателя в контрольной группе. Так, по грудным мышцам эта разница составила $0,31-1,43 \%$, а по ножным на $0,8-2,28 \%$ (в среднем). Отмечена более высокая сочность грудных мышц, а также мышц курочек по сравнению с петушками.

Включение в рацион цыплятбройлеров препарата «Экофильтрум» способствовало повышению нежности мышц. Особенно грудных мышц курочек в 3-й и 4-й, и петушков в 3-й опытной группе на 8,$44 ; 8,93$ и 9,33\% соответственно, а также ножных мышц курочек в 3-й группе на 10,46\%. Грудные мышцы курочек были более нежными, и этот показатель находился в пределах 4,03-4,39 мм.

Отмечено существенное снижение уровня кадмия и свинца в печени и почках птицы. Так, у бройлеров опытных групп, которые дополнительно получали «Экофильтрум», остаточный уровень кадмия в печени и почках снизился соответственно в 1,45-2,23 и 1,49-2,68 раза, а уровень свинца в 1,27-1,64 и 1,24-1,94 раза по сравнению с контролем. Это дает основание считать, что мясо цыплят-бройлеров, выращенных с применением препарата «Экофильтрум», является вполне безопасным продуктом.

Для оценки вкусовых качеств мяса бройлеров при использовании препарата была проведена дегустация по пятибалль- 
ной шкале в соответствии с методикой ВНИТИП.

При дегустации мяса все опытные группы получили оценки выше, чем контрольная: на 0,01-0,24 балла (жареное мясо из грудных мышц), 0,11-0,31 (жареное мясо из ножных мышц), 0,02-0,25 (вареное мясо из грудных мышц), на 0,01-0,24 балла (вареное мясо из ножных мышц).

Для бульонов была характерна достаточно выраженная наваристость и ощущение мясного вкуса. Наиболее высоко оценены вкусовые и ароматические достоинства бульона в 3-й опытной группе - на 4,53 балла, а в 1-й контрольной группе - на 4,39 балла.

Не выявлено существенных различий по показателям качества мяса и бульона между опытными группам, бройлеров получавшими разные дозы препарата «Экофильтрум».

Мясо цыплят всех групп характеризовалось как сочное, нежное, ароматное, без постороннего вкуса и запаха. Во всех случаях применения препарата «Экофильтрум» в рационах бройлеров, получаемая продукция не имела каких-либо отклонений от принятых норм и стандартов.

4. Результатьл производственной проверки.

Результаты производственной проверки представлены в таблице 7. Анализируя полученные в результате производствен- ной проверки данные, следует отметить, что они в целом подтвердили результаты предыдущего опыта. Установлено, что при использовании препарата «Экофильтрум» живая масса цыплят-бройлеров опытной группы в новом варианте выращивания повысилась на 5,19\%. Среднесуточный прирост вырос на 5,29\% по сравнению с контролем. На 4,35\% снизились затраты корма на 1 кг прироста живой массы у цыплят опытной группы. Сохранность бройлеров опытной группы была выше на $3,42 \%$ по сравнению с контрольной. Индекс продуктивности в группе, получавшей препарат «Экофильтрум», был выше на 38, 17 единиц.

В результате повышения продуктивности и сохранности бройлеров при использовании препарата «Экофильтрум» себестоимость 1 кг мяса бройлеров в опытной группе была ниже на 4,05 руб. или на $6,14 \%$, чем в контрольной. Рентабельность производства в опытной группе была на 6,7\% выше по сравнению с контролем.

Экономический эффект от использования данного препарата на поголовье 3000 бройлеров за один технологический цикл выращивания составляет около 30000 руб. При производственном цикле 6,8 оборотов в год ожидаемый экономический эффект составит около 200000 руб.

Таблица 7 - Результаты производственной проверки

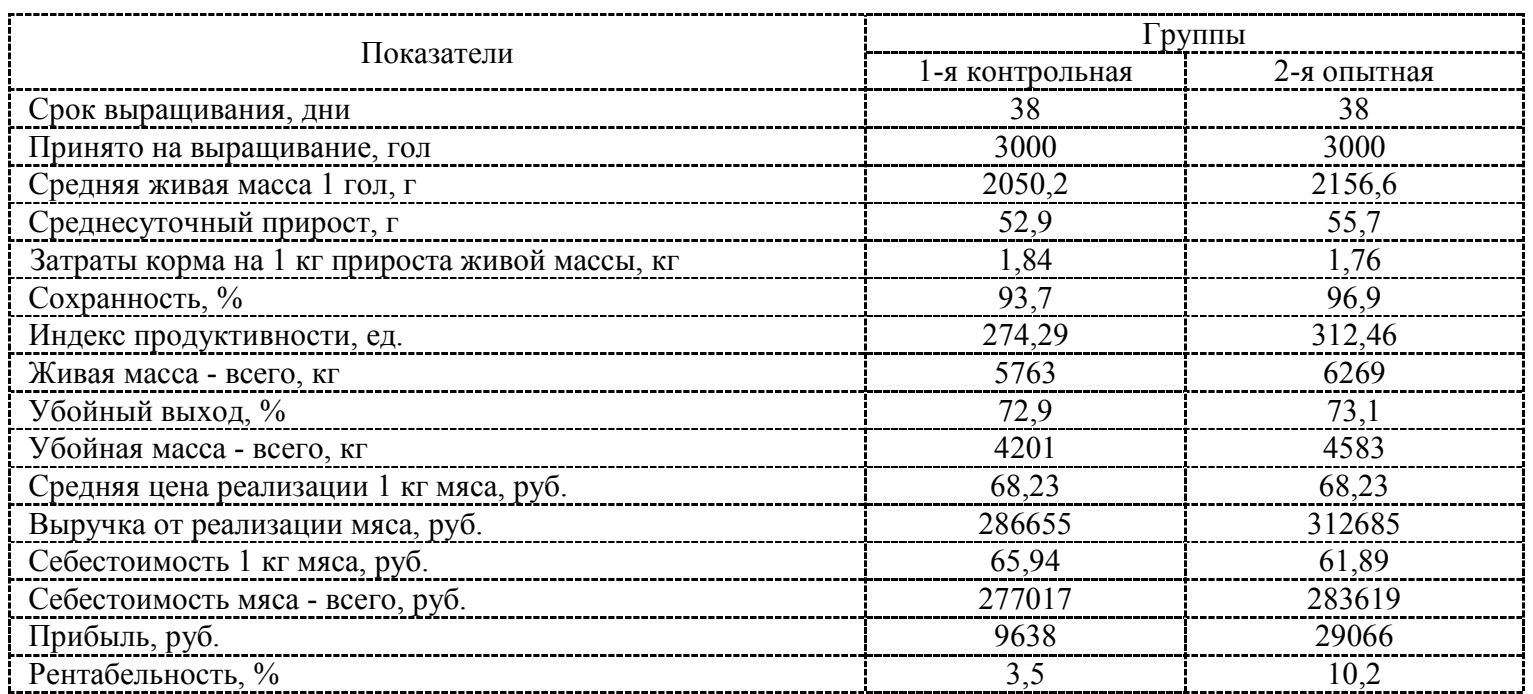




\section{Выводы:}

1. Препарат «Экофильтрум» положительно влияет на продуктивность и жизнеспособность цыплят-бройлеров. При этом следует отметить, что из всех опытных групп лучшие результаты получены в 3-й группе при включении в комбикорма для бройлеров 0,8 кг/т препарата «Экофильтрум».

2. Изучаемый препарат способствует оптимизации обменных процессов в организме птицы посредством увеличения содержания в крови эритроцитов, гемоглобина, общего белка, альбуминов и глобулинов. Полученные данные говорят о том, что у бройлеров опытных групп, более высокие показатели неспецифической резистентности организма, что находит отра- жение в повышении сохранности и продуктивности птицы.

3. В результате проведенных исследований установлено, что по комплексу показателей мясо цыплят-бройлеров, выращенных с использованием препарата «Экофильтрум», имеет более высокие характеристики качества по сравнению с контролем.

4. Производственная проверка с включением в рацион цыплят-бройлеров препарата «Экофильтрум» в дозе 0,8 кг на 1 т комбикорма подтвердила основные результаты проведенных исследований. Уровень рентабельности в новом варианте составил $10,2 \%$, что на $6,7 \%$ выше, чем в базовом варианте.

\section{БИБЛИОГРАФИЯ}

Гулюшин, С. Эффективность применения пребиотика Агримос в комбикормах для бройлеров [Текст] / C. Гулюшин, Н. Садовникова, И. Рябчик // Птицеводство. - 2010. - №5. C. 11-12.

Гущин, В.В. Выход отечественной птицепродукции на международные рынки: задача и пути ее решения [Текст] / В.В. Гущин // Птица и птицепродукты. - 2011. - №2. - С.3133.

Егоров, И.А. Развитие новых направлений в области селекции, кормления и технологии бройлерного птицеводства [Текст]/ И.А. Егоров, В.С. Буяров // Вестник Орел ГАУ.-2012.№6.-C.17-23.

Егоров, И.А. Пробиотик «Терацид-С» в комбикормах для бройлеров без антибиотиков [Текст] / И.А. Егоров, Ш.А. К.В. Имангулов, Харламов, П.Н. Паньков, Б.Л. Розанов, Т.В. Егорова, В.Д. Харитонов, Е.В. Райдна // Птица и птицепродукты. 2007. - №3. - C. 35-36.

Мамиконян, М.Л. Сценарное мышление как фактор конкурентоспособности в мясной отрасли [Текст] / М.Л. Мамиконян // Мясной ряд. - 2010. №1. - C.14-17.
Мартыновченко, В. Использование энзимо-пребиотических комплексов для бройлеров [Текст] / В. Мартыновченко, А. Васильев // Птицеводство. - 2010. - №10. - С. 27-29.

Паршин, П.А. Фармакодинамика и эффективность кормовой добавки ориган [Текст] / П.А. Паршин, С.В. Енгашев, И.А. Егоров, Н.Я. Чеснокова // Ветеринария. - 2006. - №10. - С. 12-15.

Фисинин, В.И. Инновационные направления промышленного птицеводства [Текст] / В.И. Фисинин // Птицепром. - 2011. - №2. - С. 14-23.

Хорошевская, Л. Влияние Экофильтрума на рост и развитие цыплят / Л. Хорошевская, А. Хорошевский, Т. Донцова, А. Анохин // Птицеводство. - 2010. - №8. - C. 33-34.

Clark Ed. 10 ideas that will change poultry nutrition and health // Feed International. - 2009. - Vol. 30. - № 6. - P. $10-11$. 